\title{
Editorials
}

\section{The GP's role in promoting winter wellness}

Every year in the UK there is a seasonal peak in morbidity and mortality during the coldest months. GPs have an important role in promoting winter wellness and we would like to advocate GPs placing more emphasis on a proactive approach designed to reduce risk among vulnerable individuals and families. Although some of the activities we already undertake contribute to this goal, others fall short, and few of us promote winter wellness in a coordinated way across our health and social care community. To maximise our effectiveness, primary care teams should be aware of the modifiable risk factors for excess winter mortality and morbidity; and actively manage these as part of planned as well as opportunistic care.

\section{EXCESS WINTER MORTALITY — THE CASE FOR INTERVENTION}

The Office for National Statistics calculates Excess Winter Mortality (EWM), the difference between the number of deaths in the coldest months, December to March, compared with the average number of deaths in the preceding autumn and following spring." EWM fluctuates annually due to differences in weather conditions and circulating influenza viruses. Winter 2014-2015 was a particularly bad year with almost 44000 excess winter deaths, largely attributed to the circulation of a drifted influenza A(H3N2) strain that particularly affected older people and was the cause of many care home outbreaks. Provisional data from 2015-2016 estimate 24300 excess winter deaths, less than the previous year. Although excess winter deaths are due to a range of factors, influenza is an important contributor. The 2015/2016 influenza season was dominated by the circulation of $\mathrm{A}(\mathrm{H} 1 \mathrm{~N} 1)$ pdm09, where the impact falls predominately on younger people. In addition, the influenza vaccine has been a better match to circulating strains and effectiveness has been greater: 34.3\% 195\% $\mathrm{Cl}=17.8$ to 47.5$)$ versus $54.5 \%(95 \% \mathrm{Cl}=41.6$ to 64.5$)$ against influenza $A(H 3 N 2)$ for the 2014-2015 winter period, respectively. ${ }^{2}$

EWM cannot be attributed to a single factor. It is the result of a complex set of socioeconomic and environmental factors, many of which are modifiable. Most EWM occurs in people aged over 75 years and those with long-term conditions (LTCS). Hypothermia from direct exposure to cold is a rare cause of death; rather, cold marks a tipping point towards increased unplanned

absolute winter temperatures correlate poorly with adverse outcomes; cold countries like Finland have much lower rates of excess winter mortality than the UK.

hospital admissions and deaths. Although EWM is a global phenomenon, absolute winter temperatures correlate poorly with adverse outcomes; cold countries like Finland have much lower rates of excess winter mortality than the UK. ${ }^{3}$

After age, LTCs, and influenza, cold housing is one of the most important contributors to winter mortality and morbidity. There is an almost threefold excess in winter deaths in the coldest quartile of housing compared with the warmest. ${ }^{4}$ Age of property and poor thermal efficiency ratings arealso detrimental to winter health. ${ }^{5}$ This may be one of the reasons for worse outcomes compared with our colder European counterparts. There is a poor correlation between EWM and socioeconomic deprivation, because much of the UK's social housing is better insulated and more energy efficient than owneroccupied or private rented sector homes. ${ }^{4}$

The costs of the seasonal rise in morbidity and mortality are considerable. The winter months can be marred by unexpected hospital admission and premature death. The financial costs associated with the seasonal rise in non-elective hospital admission are estimated at $£ 1.36$ billion annually, ${ }^{6}$ and there is an immense unquantified cost to the social care sector. In England, EWM is an indicator within the Public Health Outcomes Framework, and new National Institute for Health and Care Excellence (NICE) guidance details best practice. The Cold Weather Plan for England offers a framework to reduce the risks to health from cold weather by all parts of the health and social care community. ${ }^{8}$

\section{PLANNED PRE-SEASONAL INTERVENTIONS}

Delivery of high-level planned care to reduce winter risks should start in April with the new care planning cycle, and continue throughout the year. It should make the most of every opportunity to reduce vulnerability rather than just focus on emergency winter responses.

Pre-winter reviews should focus on LTC optimisation, especially cardiovascular and respiratory, which together are responsible for the majority of EWM. ${ }^{1}$ Cold temperatures increase systolic blood pressure and blood viscosity, raising the risk of strokes and heart attacks, as well as reducing the protective function of the respiratory tract. In 2015/2016, $41 \%$ more people died from respiratory diseases in the winter relative to the nonwinter period, with pneumonia accounting for the largest proportion of these excess respiratory deaths. In total, 14\% more people died from circulatory diseases relative to the non-winter months. ${ }^{1}$ Although influenza itself is rarely a direct cause of death, it is often a significant destabilising factor in winter wellness. Flu and pneumococcal vaccination coverage should be comprehensive in all eligible groups.

Primary care teams should be trained to identify patients who might be at risk from a cold home and from fuel poverty (Box 1). ${ }^{9}$ Fuel poverty is defined as households with above-average fuel costs and a residual income that would fall below the poverty line if they were to pay those costs Iresidual income is the amount left in a household weekly or monthly cycle after all major expenses have been met). Fuel poverty is surprisingly prevalent, affecting $10.6 \%$ of all English households. ${ }^{10}$ Fuel-poor homes may have indoor temperatures below the recommended $18^{\circ} \mathrm{C}\left(65^{\circ} \mathrm{F}\right)$, but fuel poverty is not the only reason for cold homes. Other reasons include difficulty using heating systems, reduced mobility, or personal values such as thrift and stoicism. Most English local authorities now have single-point-ofaccess housing and energy advice services that can help,11 often in partnership with health and third-sector organisations. Heath localities should ensure that care planning includes assessment of housing conditions, with a particular emphasis on identification of people whose health may be at risk from cold homes, and ensure all frontline health and social care staff are trained both to identify the risk and know how to access assistance for their patients locally.

Clinicians should carefully consider how and when they might provide 'rescue packs' of 


\section{Box 1. Identifying individuals whose health may be at risk from a cold home?}

Clues about exposure to cold that may be picked up during questioning. Patients may say:

- my home is often too cold, draughty, or damp

- my fuel/energy bills are too high;

- I often have to borrow money for fuel/ electricity/gas;

- I use a pre-payment meter to avoid running up debt;

- I often stay in bed to keep warm;

- I often sit with a hot water bottle;

- I try to keep warm elsewhere; or

- I want to stay in hospital because it is more comfortable.

Clues picked up on home visits by health and social care professionals:

- feels cold or draughty

- smells of damp;

- no visible form of heating;

- only heating comes from electric fires, fan heaters, oil-filled radiators, or bottled gas;

- only one room is heated

- draught-proofing is inadequate;

- ventilators have been blocked up or covered;

- wearing lots of clothes indoors

- curtains are closed in the day to keep the heat in; or

- signs of damp such as: pools on window sills mouldy patches around windows, outer walls, ceilings, or upper corners of upstairs rooms.

antibiotics and steroids for those with airway disease to allow them to self-medicate in exacerbations; ${ }^{12}$ and how and when they use influenza antiviral medications, particularly if they look after residential institutions for treatment and prophylaxis purposes. ${ }^{13}$ Both need careful consideration in a population so vulnerable to excess mortality.

\section{OPPORTUNISTIC SEASONAL \\ INTERVENTIONS}

The GP's role is usually focused on avoidance of unnecessary hospital admission, and should include asking about a patient's home circumstances. Even during the cold months opportunity exists to modify risk factors associated with poor housing and cold homes. Although we recognise there are currently no validated tools for identifying patients in cold homes, every vulnerable patient contact should include attention to living conditions and indoor temperature, especially on home visits and after discharge from hospital. Urgent winter warmth services may be available through their local authority or third-sector organisations. Age UK, other national charities, and many smaller local organisations offer a multitude of activities from day centres to befrienders.

Finally, GPs must identify and support patients suffering from social isolation, a particular problem in the winter as cold weather can deter people from going out and decreased activity levels may contribute to EWM.

\section{CONCLUSION}

GPs and commissioners of health and social care should work together to develop local services aimed at promoting winter wellness and reducing winter morbidity and EWM. The focus should shift from one of avoiding admission at the point of crisis to getting upstream and ensure our care planning process:

- optimises LTC management, particularly of cardiovascular and respiratory disease;

- achieves higher levels of influenza and pneumococcal vaccine uptake; and

- ensures our patients have warm housing. This should be seen as an essential element of care planning. We should flag patients at risk and have clear referral pathways that make best use of local and national support services.

\section{Daniel Gordon,}

GP Registrar, Keats Group Practice, London.

\section{ADDRESS FOR CORRESPONDENCE}

\section{Daniel Gordon}

Keats Group Practice, 1B Downshire Hill, London NW3 1NR, UK.

\section{E-mail: danielgordonadoctors.org.uk}

\section{Angie Bone,}

Consultant in Public Health Medicine, Head of Extreme Events and Health Protection, Centre for Radiation, Chemicals and Environmental Hazards, Public Health England, London.

\section{Richard Pebody}

Head (acting), Respiratory Diseases Department, Head, Influenza and Other Respiratory Virus Surveillance Section, National Infections Service, Public Health England, London.

\section{Simon de Lusignan}

Professor of Primary Care and Clinical Informatics, Chair in Health Care Management, Department of Clinical and Experimental Medicine, University of Surrey, Guildford.

\section{Provenance}

Commissioned; externally peer reviewed.

\section{REFERENCES}

1. Office for National Statistics. Excess winter mortality in England and Wales: 2015/16 (provisional) and 2014/15 (final). 2016.

2. Pebody R, Warburton F, Ellis J, et al. Effectiveness of seasonal influenza vaccine for adults and children in preventing laboratoryconfirmed influenza in primary care in the United Kingdom: 2015/16 end-of-season results. Euro Surveill 2016; 21(38). DOI: 10.2807/1560-7917.ES.2016.21.38.30348

3. Fowler T, Southgate RJ, Waite T, et al. Excess winter deaths in Europe: a multi-country descriptive analysis. Eur J Public Health 2015; 25(2): 339-345.

4. Marmot M, Geddes I, Bloomer E, et al. The health impacts of cold homes and fuel poverty. Written by the Marmot Review Team for Friends of the Earth. 2011. http://wnw. instituteofhealthequity.org/projects/the-healthimpacts-of-cold-homes-and-fuel-poverty/ the-health-impacts-of-cold-homes-and-fuelpoverty-full-report.pdf laccessed 9 Jan 2017).

5. Wilkinson P, Armstrong A, Landon M, et al. Cold comfort: the social and environmental determinants of excess winter deaths in England, 1986-1996. Bristol: Policy Press, 2001.

6. Age UK. The cost of cold: why we need to protect the health of older people in winter 2012. http://www.ageuk.org.uk/Documents/ EN-GB/Campaigns/The_cost_of_cold_2012. pdf?dtrk=true laccessed 9 Jan 2017).

7. National Institute for Health and Care Excellence. Excess winter deaths and illness and the health risks associated with cold homes. NG6. London: NICE, 2015. https://www. nice.org.uk/guidance/ng6 laccessed 9 Jan 2017).

8. Public Health England. The cold weather plan for England: protecting health and reducing harm from cold weather. 2015. https://wnw. gov.uk/government/uploads/system/uploads/ attachment_data/file/576152/Cold_weather plan_2016.pdf (accessed 9 Jan 2017).

9. UK Health Forum. Fuel poverty: tackling cold homes and ill-health. A guide for primary care. 2014. http://nhfshare. heartforum.org.uk/RMAssets/HealthyPlaces/ PrimaryCareGuidance_HP.pdf laccessed 9 Jan 2017).

10. Department of Energy and Climate Change Annual fuel poverty statistics report, 2016 (England). 2016. https://unw.gov.uk/ government/uploads/system/uploads/ attachment_data/file/557400/Annual_ Fuel_Poverty_Statistics_Report_2016_revised_30.09.2016.pdf (accessed 9 Jan 2017).

11. Department of Energy and Climate Change. Catalogue of health-related fuel poverty schemes. 2015. https://www.gov. uk/government/uploads/system/uploads/ attachment_data/file/451025/DECC_FINAL.pdf (accessed 9 Jan 2017).

12. Davies F, Risør MB, Melbye $H$, et al. Primary and secondary care clinicians' views on self-treatment of COPD exacerbations: a multinational qualitative study. Patient Educ Couns 2014; 96(2): 256-263.

13. Santesso N, Hsu J, Mustafa R, et al. Antivirals for influenza: a summary of a systematic review and meta-analysis of observational studies. Influenza and Other Respir Viruses 2013; 7(Suppl 2): 76-81. 